\title{
Phenytoin induced toxic epidermal necrolysis: a case report
}

\author{
Sandipan Barkakaty, Girish K.*
}

Department of Pharmacology, KIMS Bangalore, RGUHS, Karnataka, India

Received: 09 March 2019

Revised: 02 April 2019

Accepted: 03 May 2019

*Correspondence to:

Dr. Girish K.,

Email: drgirish_k@

rediffmail.com

Copyright: (C) the author(s), publisher and licensee Medip Academy. This is an openaccess article distributed under the terms of the Creative Commons Attribution NonCommercial License, which permits unrestricted noncommercial use, distribution, and reproduction in any medium, provided the original work is properly cited.

\begin{abstract}
Stevens Johnson syndrome (SJS) and toxic epidermal necrolysis (TEN), are severe idiosyncratic reactions characterized by fever and mucocutaneous lesions leading to necrosis and sloughing of the epidermis. The usage of anticonvulsants like carbamazepine, phenytoin, lamotrigine, phenobarbital are associated with high risk for occurrence of TEN. We present a case of toxic epidermal necrolysis in a 30 year old female probably induced by phenytoin. A 30 year old female was admitted to the emergency medicine department of KIMS hospital, Bengaluru. Lesions over the lips and oral cavity, multiple fluid filled blisters were present diffusely all over the body. Patient had a past history of oral cavity lesions with injection phenytoin. Patient is a known epileptic of over 12 years and was on treatment. Patient had a seizure attack 3 days back and visited nearby hospital and did not inform the doctor of her allergy to phenytoin. Patient was given inj phenytoin after which she developed oral lesions and also presented with fluid filled bullae all over the body. A diagnosis of toxic epidermal necrolysis was made based on clinical history and Scoreten score and was treated with betadine wash, fluconazole and antibiotics. The lesions improved significantly with the above management and patient recovered enough to be discharged from the hospital after 5 days. Severe and serious reactions such as toxic epidermal necrolysis can be caused by commonly used drugs like phenytoin.
\end{abstract}

Keywords: Adverse drug reaction, Hartwig's severity assessment scale, Naranjo's adverse drug reaction probability scale, Phenytoin, Scoreten score, Toxic epidermal necrolysis

\section{INTRODUCTION}

Stevens Johnson syndrome (SJS) and Toxic Epidermal Necrolysis (TEN) are severe idiosyncratic reactions characterized by fever and mucocutaneous lesions leading to necrosis and sloughing of the epidermis. The percentage of epidermal detachment is the primary differentiating factor, SJS presenting with $<10 \%$ epidermal detachment and TEN presenting with $>30 \%$; while cases between $10 \%$ and $30 \%$ of involvement are defined as SJS-TEN overlap. The usage of anticonvulsants like carbamazepine, phenytoin, lamotrigine, phenobarbital are associated with high risk for occurrence of TEN. Incidence rate of
Phenytoin induced mucocutaneous reactions is $13.37 \%$ in India . More than $90 \%$ of SJS and TEN cases occurred in the first 63 days of anti- epileptic drug use. ${ }^{1}$ This study present a case of toxic epidermal necrolysis in a 30 year old female probably induced by phenytoin.

Phenytoin (or its prodrug, fosphenytoin) is a widely used medication for common types of epileptic seizures, especially when accompanied by focal brain lesions. Available in parenteral and oral forms, phenytoin is widely used. Despite the inherited risk of dose-related toxicity attributed to its zero-order pharmacokinetics, phenytoin is still considered a first-line therapy for some types of 
seizures. Thus, therapeutic monitoring of a patient's phenytoin serum level is crucial to assure the safety and efficacy of phenytoin therapy. ${ }^{2}$

\section{CASE REPORT}

A 30 year old female was admitted to the emergency medicine department of KIMS hospital, Bengaluru. Lesions over the lips and oral cavity (Figure 1), lesions over the upper extremities (Figure 2), multiple fluid filled blisters were present diffusely all over the body (Figure 3 ).

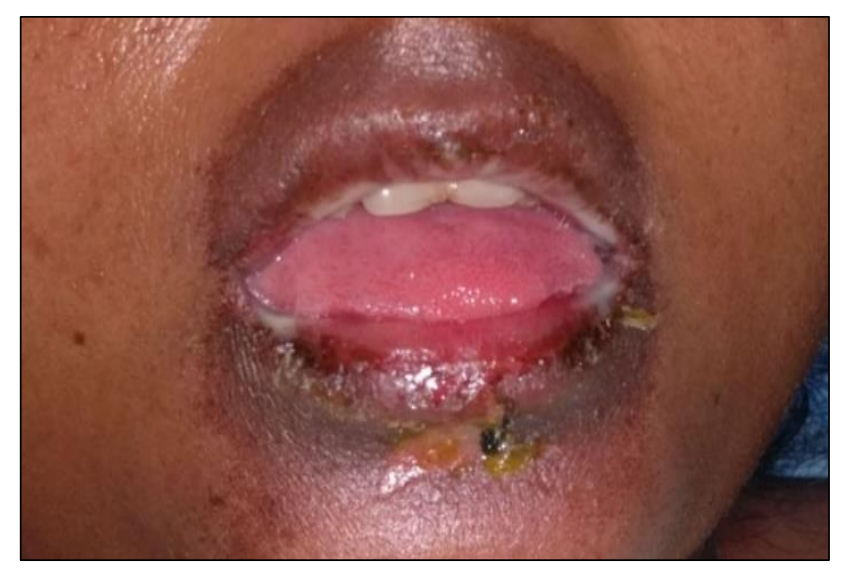

Figure 1: Lesions over the lips and oral cavity.

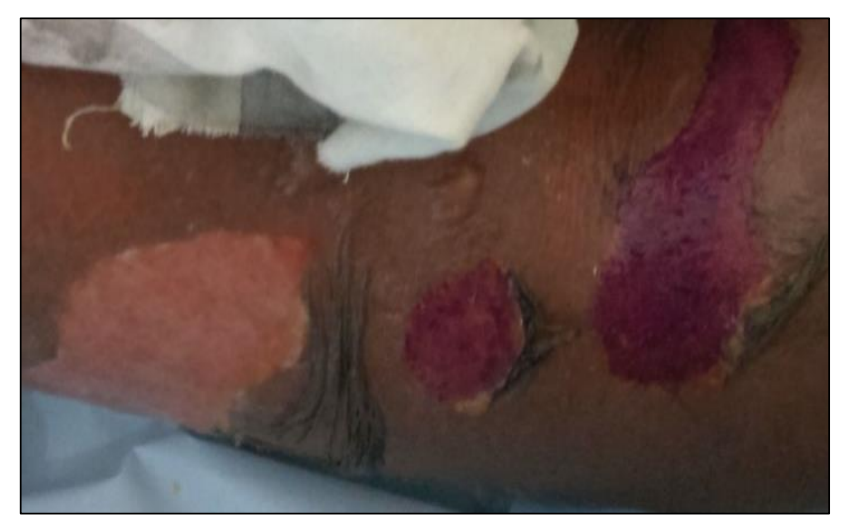

Figure 2: Lesions over upper extremities.

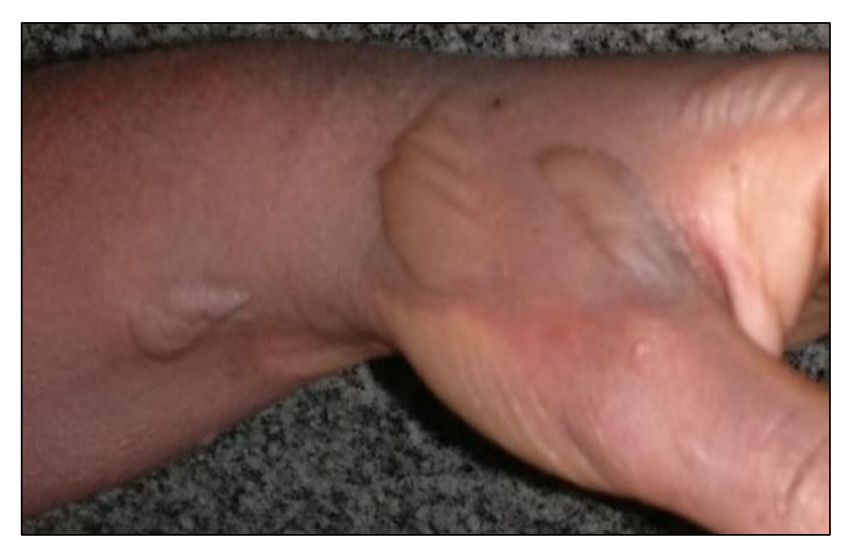

Figure 3: Fluid filled blisters over extremities.
Patient had a past history of oral cavity lesions with injection phenytoin. Patient is a known epileptic of over 12 years and was on treatment. Patient had a seizure attack 3 days back and visited nearby hospital and did not inform the doctor of her allergy to phenytoin. Patient was given inj phenytoin after which she developed oral lesions and also presented with fluid filled bullae all over the body. A diagnosis of toxic epidermal necrolysis was made based on clinical history and Scoreten score and was treated with betadine wash, fluconazole and antibiotics. The lesions improved significantly with the above management and patient recovered enough to be discharged from the hospital after 5 days.

\section{DISCUSSION}

Toxic epidermal necrolysis (TEN) and Steven Johnson Syndrome (SJS) are considered to be two ends of a spectrum of severe, life threatening epidermolytic cutaneous adverse drug reactions, differing only by their extent of skin detachment. Anticonvulsants like phenytoin are a major cause of TEN and other severe cutaneous reactions. Symptoms of toxic epidermal necrolysis are mostly cutaneous to start with and may involve mucous membranes and further body systems if not addressed. We have attempted to co-relate the findings in our patient with the available facts related to the same. In our study the Scoreten score is 2 (Table 1), Naranjo's causality assessment is probable (Table 2), WHO-UMC causality assessment is probable/likely (Table 3), Hartwig's severity assessment scale was level 5- severe (Table 4), and Schumock and Thornton preventability scale- definitely preventable (Table 5).

\section{Table 1: Severity-of-illness score for ten. ${ }^{3}$}

\begin{tabular}{|ll|}
\hline Scoreten score & Score \\
\hline Age more than 40 years & 0 \\
\hline Malignancy & 0 \\
\hline Heart rate $>120 /$ minute & 0 \\
\hline Initial epidermal detachment $>10 \%$ of BSA & 1 \\
\hline $\begin{array}{l}\text { Serum urea level }>28 \mathrm{mg} / \mathrm{dl}(40 \mathrm{mg} / \mathrm{dl} \text { in } \\
\text { Indian settings })\end{array}$ & 0 \\
\hline Serum bicarbonate levels $<20 \mathrm{mEq} / \mathrm{dl}$. & 1 \\
\hline Serum glucose levels $>250 \mathrm{mg} / \mathrm{dl}$ & 0 \\
\hline Total score & 2 \\
\hline
\end{tabular}

The probability of death predicted by this score : $0-1$ points-3\%; 2 points- $12 \%$; 3 points- $35 \%$; 4 points- $58 \%$; 5 to 7 points- $90 \%$

Table 6 gives an analysis of the ADR. Genetic basis for these ADRs like SJS/TEN have been attributed to inherited or acquired deficiency in phase 2 detoxification enzymes or from an elevated cytochrome P450 (CYP 450) isoform(s). Few studies have also indicated an association between HLA*1502 and phenytoin induced SJS/TEN ${ }^{6}$. Thereby, it is recommended to first screen the patients for this particular allele before starting with antiepileptic drugs. Factors associated with increased risk of this reaction include the use of higher than recommended dose, 
more rapid dose escalation and concomitant use of valproate $^{7}$. Study conducted by Sheer et al, revealed that CYP 450 is involved in the metabolism of phenytoin and a defect in epoxide hydrolases lead to accumulation of reactive metabolites like arene oxides ${ }^{8}$. Family history of such reactions should always be asked by the prescribing doctor before prescribing these medicines. Additionally, this case reflects an important aspect of pharmacotherapy namely "Medication Errors." In this case the patient had a known allergy to phenytoin. Such medication errors due to negligence account for about $1 \%$ of all hospital admissions which could be prevented.

Table 2: Naranjo's ADR causality assessment. ${ }^{4}$

\begin{tabular}{|c|c|c|c|c|}
\hline Question & Yes & No & Do not know & Score \\
\hline 1. Are there previous conclusive reports on this reaction? & +1 & 0 & 0 & 1 \\
\hline $\begin{array}{l}\text { 2. Did the adverse event appear after the suspected drug was } \\
\text { administered? }\end{array}$ & +2 & -1 & 0 & 2 \\
\hline $\begin{array}{l}\text { 3. Did the adverse reaction improve when the drug was discontinued or a } \\
\text { specific antagonist was administered? }\end{array}$ & +1 & 0 & 0 & 1 \\
\hline 4. Did the adverse event reappear when the drug was re-administered? & +2 & -1 & 0 & 0 \\
\hline $\begin{array}{l}\text { 5. Are there alternative causes (other than the drug) that could on their } \\
\text { own have caused the reaction? }\end{array}$ & -1 & +2 & 0 & 0 \\
\hline 6. Did the reaction reappear when a placebo was given? & -1 & +1 & 0 & 0 \\
\hline $\begin{array}{l}\text { 7. Was the drug detected in blood (or other fluids) in concentrations } \\
\text { known to be toxic? }\end{array}$ & +1 & 0 & 0 & 0 \\
\hline $\begin{array}{l}\text { 8. Was the reaction more severe when the dose was increased or less } \\
\text { severe when the dose was decreased? }\end{array}$ & +1 & 0 & 0 & 0 \\
\hline $\begin{array}{l}\text { 9. Did the patient have a similar reaction to the same or similar drugs in } \\
\text { any previous exposure? }\end{array}$ & +1 & 0 & 0 & 1 \\
\hline 10. Was the adverse event confirmed by any objective evidence? & +1 & 0 & 0 & 0 \\
\hline Total & & & & 5 \\
\hline
\end{tabular}

Score: $\geq 9=$ definite ADR; 5-8=probable ADR; 1-4=possible ADR; 0=doubtful AD

Table 3: WHO-UMC Causality assessment. ${ }^{4}$

\begin{tabular}{|c|c|}
\hline Causality term & Assessment criteria* \\
\hline \multirow{5}{*}{ Certain } & Event or laboratory test abnormality, with plausible time relationship to drug intake \\
\hline & Cannot be explained by disease or other drugs \\
\hline & Response to withdrawal plausible (pharmacologically, pathologically \\
\hline & $\begin{array}{l}\text { Event definitive pharmacologically or phenomenologically (i.e. an objective and specific medical } \\
\text { disorder or a recognized pharmacological phenomenon) }\end{array}$ \\
\hline & Rechallenge satisfactory, if necessary \\
\hline \multirow{4}{*}{ Probable/ likely } & Event or laboratory test abnormality, with reasonable time relationship to drug intake \\
\hline & Unlikely to be attributed to disease or other drugs \\
\hline & Response to withdrawal clinically reasonable \\
\hline & Rechallenge not required \\
\hline \multirow{3}{*}{ Possible } & Event or laboratory test abnormality, with reasonable time relationship to drug intake \\
\hline & Could also be explained by disease or other drugs \\
\hline & Information on drug withdrawal may be lacking or unclear \\
\hline \multirow[t]{2}{*}{ Unlikely } & $\begin{array}{l}\text { Event or laboratory test abnormality, with a time to drug intake that makes a relationship improbable } \\
\text { (but not impossible) }\end{array}$ \\
\hline & Disease or other drugs provide plausible explanations \\
\hline \multirow{3}{*}{$\begin{array}{l}\text { Conditional/ } \\
\text { unclassified }\end{array}$} & Event or laboratory test abnormality \\
\hline & More data for proper assessment needed, or \\
\hline & Additional data under examination \\
\hline \multirow{3}{*}{$\begin{array}{l}\text { Unassessable/ } \\
\text { unclassifiable }\end{array}$} & Report suggesting an adverse reaction \\
\hline & Cannot be judged because information is insufficient or contradictory \\
\hline & Data cannot be supplemented or verified \\
\hline
\end{tabular}


Table 4: Hartwig's severity assessment scale. ${ }^{5}$

\begin{tabular}{|c|c|}
\hline Level & Assessment scale \\
\hline Level 1 & An ADR occurred but required no change in treatment with the suspected drug. \\
\hline Level 2 & $\begin{array}{l}\text { The ADR required that treatment with the suspected drug be held, discontinued, or otherwise changed. No } \\
\text { antidote or other treatment requirement was required. No increase in length of stay (LOS). }\end{array}$ \\
\hline Level 3 & $\begin{array}{l}\text { The ADR required that treatment with the suspected drug be held, discontinued, or otherwise changed. } \\
\text { AND/OR an Antidote or other treatment was required. No increase in length of stay (LOS). }\end{array}$ \\
\hline Level 4 & $\begin{array}{l}\text { Any level } 3 \text { ADR which increases length of stay by at least } 1 \text { day (OR) The ADR was the reason for } \\
\text { admission. }\end{array}$ \\
\hline Level 5 & Any level 4 ADR which requires intensive medical care. \\
\hline Level 6 & The adverse reaction caused permanent harm to the patient. \\
\hline Level 7 & The adverse reaction either directly or indirectly led to the death of the patient. \\
\hline
\end{tabular}

Table 5: ADR preventability assessment.

\begin{tabular}{|l|l|}
\hline Definitely preventable \\
\hline 1 & Was there a history of allergy or previous reactions to the drug?- YES \\
\hline 2 & Was the drug involved inappropriate for the patient's clinical condition? \\
\hline 3 & Was the dose, route or frequency of administration inappropriate for the patient's age, weight or disease state? \\
\hline 4 & Was a toxic serum drug concentration (or laboratory monitoring test) documented? \\
\hline 5 & Was there a known treatment for the adverse drug reaction? \\
\hline Probably preventable \\
\hline 6 & Was required therapeutic drug monitoring or other necessary laboratory tests not performed? \\
\hline 7 & Was a drug interaction involved in the ADR? \\
\hline 8 & Was poor compliance involved in the ADR? \\
\hline 9 & Were preventative measures not prescribed or administered to the patient? \\
\hline Not preventable \\
\hline 1 & If all above criteria not fulfilled \\
\hline
\end{tabular}

Table 6: Analysis of the ADR.

\begin{tabular}{|ll|}
\hline Parameters & \\
\hline Causality - Naranjo & Probable \\
\hline Causality - WHO-UMC & Probable/likely \\
\hline Severity - Hartwig & Severe \\
\hline $\begin{array}{l}\text { Preventability- Schumock } \\
\text { and Thornton }\end{array}$ & Definitely preventable \\
\hline
\end{tabular}

\section{CONCLUSION}

TEN is a severe life threatening complication associated with use of anticonvulsants like phenytoin which may have familial tendency. As the adverse systemic reactions to antiepileptic drugs (AEDs) are rare and severe, physicians should counsel patients on the importance of notifying their physician if they develop any unusual symptoms. It is also advisable to give personal "allergy card"- in the true sense being an alert card about the description of ADR to the patient who suffered from such serious reactions.

Funding: No funding sources Conflict of interest: None declared Ethical approval: Not required

\section{REFERENCES}

1. Mockenhaupt $\mathrm{M}$, Messenheimer $\mathrm{J}$, Tennis $\mathrm{P}$, Schlingmann J. Risk of Stevens-Johnson syndrome and toxic epidermal necrolysis in new users of antiepileptics. Neurology. 2005 Apr 12;64(7):1134-8.

2. Glick TH, Workman TP, Gaufberg SV. Preventing phenytoin intoxication: safer use of a familiar anticonvulsant. J Fam Pract. 2004 Mar;53(3):197202.

3. Bastuji-Garin S, Fouchard N, Bertocchi M, Roujeau JC, Revuz J, Wolkenstein P. SCORTEN: a severityof-illness score for toxic epidermal necrolysis. J Invest Dermatol. 2000 Aug;115(2):149-53.

4. Zaki SA. Adverse drug reaction and causality assessment scales. Lung India. 2011;28(2):152-3.

5. Petrova G, Stoimenova A, Dimitrova M, Kamusheva M, Petrova D, Georgiev O. Assessment of the expectancy, seriousness and severity of adverse drug reactions reported for chronic obstructive pulmonary disease therapy. SAGE Open Med. 2017 Jan 31;5:2050312117690404.

6. Chung WH, Hung SI, Hong HS, Hsih MS, Yang LC, Ho HC, et al. Medical genetics: a marker for Stevens- 
Johnson syndrome. Nature. 2004 Apr 1;428(6982):486.

7. Craven NM. Management of toxic epidermal necrolysis. Hosp Med. 2000 Nov;61(11):778-81.
8. Shear NH, Spielberg SP. Anticonvulsant hypersensitivity syndrome. In vitro assessment of risk. J Clin Invest. 1988;82(6):1826-32.

Cite this article as: Barkakaty S, Girish K. Phenytoin induced toxic epidermal necrolysis: a case report. Int J Basic Clin Pharmacol 2019;8:1448-52. 